\title{
MASSA SECA E EXTRAÇÃO DE NUTRIENTES POR DUAS FORRAGEIRAS FERTIRRIGADAS COM ESGOTO DOMÉSTICO TRATADO
}

\author{
DRY MASS AND NUTRIENT EXTRACTION OF TWO FORAGE FERTIGATED WITH \\ DOMESTIC SEWAGE TREATED
}

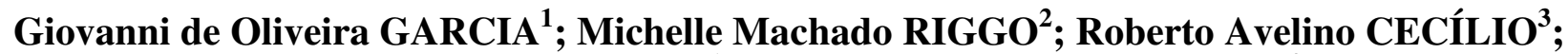 \\ Edvaldo Fialho dos REIS ${ }^{1}$; Ana Paula Almeida BERTOSSI ${ }^{4}$ \\ 1. Professor, Doutor, Universidade Federal do Espírito Santo - UFES, Alegre, ES, Brasil. giovanni.garcia@ ufes.br; 2. Doutoranda no \\ Programa de Pós-graduação em Meio Ambiente, Universidade Estadual do Rio de Janeiro, Rio de Janeiro, RJ, Brasil; 3. Professor, \\ Doutor, UFES, Jerônimo Monteiro, ES, Brasil; 4. Doutoranda do Programa de Pós-graduação em Produção Vegetal - UFES, Alegre, ES, \\ Brasil.
}

\begin{abstract}
RESUMO: Devido à pouca informação sobre a capacidade de extração de nutrientes do solo por forrageiras fertirrigadas com efluentes, o presente trabalho teve como objetivo avaliar a capacidade de extração de macronutrientes e sódio do solo pelas forrageiras Tifton 85 (Cynodon spp) e Capim Marandú (Brachiaria brizantha) fertirrigadas com esgoto doméstico tratado em três ciclos de produção, em condições de casa de vegetação. Os experimentos foram montados num delineamento inteiramente casualizado, sendo um para cada espécie, ambos no esquema em parcelas subdivididas $4 \times 3$ com 5 repetições, sendo quatro tratamentos fertirrigados com esgoto doméstico tratado nas dosagens de $20,40,60$ e $80 \mathrm{~kg}^{-1}$ de nitrogênio nas parcelas e nas subparcelas, três ciclos de produção onde foram realizados cortes no material vegetal das forrageiras, sempre aos 30 dias após o término da aplicação do esgoto doméstico tratado. Após cada corte, os tratamentos foram novamente aplicados e no material vegetal cortado foram quantificados os teores foliares dos macronutrientes e sódio extraídos do solo pelas forrageiras. Os resultados obtidos demonstraram que a aplicação de nitrogênio por meio do esgoto doméstico tratado e os ciclos de produção (cortes) afetaram positivamente a produção de massa seca e a extração dos macronutrientes e sódio pelas plantas de Tifton 85 e de Capim Marandú.
\end{abstract}

PALAVRAS-CHAVE: Reuso de água. Efluente. Cynodon spp. Brachiaria brizantha.

\section{INTRODUÇÃO}

A escassez hídrica natural em certas regiões e aquela agravada pela poluição dos corpos hídricos reduz a quantidade e qualidade deste recurso. Assim, considerando a destinação de fontes de água não poluída para o consumo humano, nos últimos anos, o avanço do conhecimento técnico-científico em relação ao potencial de reuso da água contribuiu para o aumento do interesse do uso de efluentes em cultivos agrícolas (VILLELA JÚNIOR et al., 2003).

$\mathrm{O}$ crescente volume de efluentes domésticos sem tratamento lançados nos corpos hídricos, decorrentes do aumento da população urbana, juntamente com a busca por água de fácil disponibilidade para atender estes usuários, proporciona condições de concorrência por este recurso cada vez mais limitado em sua qualidade (COSTA et al., 2002).

Em geral, o Brasil possui mais de 200 milhões de hectares com pastos e a grande parte é constituída por pastagens naturais. Normalmente, as forrageiras, não recebem nenhum tipo de adubação e com o decorrer dos anos acabam perdendo o seu potencial de desenvolvimento, reduzindo a sua qualidade e produtividade (BENETT et al., 2008). Outro aspecto é a propensão do solo aos efeitos erosivos, pois, a baixa cobertura vegetal disponibiliza áreas para o pisoteio do gado e favorece a compactação do solo diminuindo a capacidade de infiltração da água no solo (ZIMMER et al. 2002).

$\mathrm{Na}$ busca de novas tecnologias para melhoria do sistema produtivo com pastagens, a fertirrigação com o uso de efluente tem sido estudada. No Brasil, trabalhos de reutilização de efluentes em sistemas de cultivo com gramíneas forrageiras obtiveram resultados satisfatórios em relação ao aumento da qualidade e rendimento da forragem (ERTHAL et al., 2010).

Com a reutilização de efluentes tratados em sistemas de produção de forragens, as plantas utilizam os nutrientes presentes nos mesmos para o seu crescimento e desenvolvimento. Dessa forma, estas extraem parte dos nutrientes adicionados ao solo decorrentes do uso do efluente. No entanto, segundo Costa et al. (2010), torna-se importante conhecer a necessidade de nutrientes das plantas forrageiras e, consequentemente, sua capacidade de extraí-los do solo.

Segundo Costa et al. (2010) em sistemas de produção de forragens com adubação mineral, dentre os nutrientes, o nitrogênio e o potássio são os mais extraídos pelas gramíneas forrageiras. Por 
outro lado, trabalhos envolvendo a extração de nutrientes por diversas espécies de forrageiras, são em sua maioria, voltados ao tratamento de efluentes de atividades domésticas e agropecuárias. Nesse sentido, Matos et al. (2005) avaliando a capacidade de extração de nutrientes advindos de efluente da lavagem e despolpamento dos frutos do cafeeiro arábica pelo azevém e milheto, verificaram que as maiores extrações de potássio, cálcio e magnésio foram obtidas pelo azevém e as maiores remoções de nitrogênio, fósforo e sódio pelo milheto. Em outros trabalhos envolvendo o tratamento de águas residuárias por disposição no solo, espécies vegetais como o Tifton 85 (Cynodon spp.) demonstraram elevada eficiência na extração de nutrientes de águas residuárias de diversas origens (MATOS et al., 2008; 2009; 2010).

Nesse aspecto torna-se necessário o conhecimento da extração de nutrientes pelas forrageiras, especialmente em sistemas intensivos que utilizam efluentes domésticos tratados, a fim de obter índices técnicos científicos para a utilização destes resíduos e evitar prejuízos devidos a desequilíbrios nutricionais. Dessa forma por existir pouca informação sobre a capacidade de extração de nutrientes de forrageiras fertirrigadas com efluentes, objetivou-se neste trabalho avaliar a capacidade de extração de macronutrientes e sódio pelas forrageiras Tifton 85 (Cynodon spp.) e Capim Marandu (Brachiaria brizantha) em três ciclos de produção e fertirrigadas com esgoto doméstico tratado, em condições de casa de vegetação.

\section{MATERIAL E MÉTODOS}

O trabalho foi conduzido em vasos de 18 litros, no período de junho a agosto de 2010, dentro de casa de vegetação na área experimental do Centro de Ciências Agrárias da Universidade Federal do Espírito Santo localizado no município de Alegre - ES com coordenadas geográficas de latitude $20^{\circ} 45^{\prime}$ Sul, longitude $41^{\circ} 48^{\prime}$ ' Oeste e altitude de $147 \mathrm{~m}$.

O solo utilizado no enchimento dos vasos foi coletado no horizonte A do perfil natural de um Latossolo Vermelho Amarelo do qual foi retirada uma amostra e encaminhada ao laboratório para determinação dos atributos químicos (Tabela 1), segundo a metodologia descrita pela Embrapa (2009).

Tabela 1. Atributos químicos do solo utilizado no experimento

\begin{tabular}{lc}
\hline Característica & Valor \\
\hline pH em água & 6,1 \\
Enxofre $\left(\mathrm{mg} \mathrm{dm}^{-3}\right)$ & 3,0 \\
Fósforo $\left(\mathrm{mg} \mathrm{dm}^{-3}\right)$ & 2,0 \\
Potássio $\left(\mathrm{mg} \mathrm{dm}^{-3}\right)$ & 16,0 \\
Sódio $\left(\mathrm{mg} \mathrm{dm}^{-3}\right)$ & 15,0 \\
Cálcio $\left(\mathrm{cmol}_{\mathrm{c}} \mathrm{dm}^{-3}\right)$ & 0,7 \\
Magnésio $\left(\mathrm{cmol}_{\mathrm{c}} \mathrm{dm}^{-3}\right)$ & 4,9 \\
Alumínio $\left(\mathrm{cmol}_{\mathrm{c}} \mathrm{dm}^{-3}\right)$ & 0,2 \\
H+Al $\left(\mathrm{cmol}_{\mathrm{c}} \mathrm{dm}^{-3}\right)$ & 2,5 \\
Carbono $\left(\mathrm{g} \mathrm{kg}^{-1}\right)$ & 1,7 \\
Matéria Orgânica $\left(\mathrm{g} \mathrm{kg}^{-1}\right)$ & 2,9 \\
CTC efetiva $\left(\mathrm{cmol}_{\mathrm{c}} \mathrm{dm}^{-3}\right)$ & 5,8 \\
CTC total $\left(\mathrm{cmol}_{\mathrm{c}} \mathrm{dm}^{-3}\right)$ & 8,2 \\
Soma de Bases $\left(\mathrm{cmol}_{\mathrm{c}} \mathrm{dm}^{-3}\right)$ & 5,7 \\
Saturação por Bases $(\%)$ & 49,4 \\
Saturação por Alumínio $(\%)$ & 2,6 \\
Índice de Saturação por Sódio $(\%)$ & 0,8 \\
Ferro $\left(\mathrm{mg} \mathrm{dm}{ }^{-3}\right)$ & 220,0 \\
Cobre (mg dm & 1,4 \\
Zinco $\left(\mathrm{mg} \mathrm{dm}^{-3}\right)$ & 2,5 \\
Manganês $\left(\mathrm{mg} \mathrm{dm}^{-3}\right)$ & 15,0 \\
Boro $\left(\mathrm{mg} \mathrm{dm}^{-3}\right)$ & 0,1 \\
\hline
\end{tabular}


Após seco ao ar, destorroado, homogeneizado e passado em peneira com malha de $2 \mathrm{~mm}$ o solo teve sua acidez corrigida mediante a aplicação de calcário dolomítico elevando-se a saturação por bases até $60 \%$ de acordo com a recomendação proposta por Prezotti et al. (2007) para o estado do Espírito Santo no cultivo de forragens de elevada exigência nutricional.

Foram montados dois experimentos, ambos no delineamento inteiramente casualizado (DIC), sendo um com a forrageira Tifton 85 (Cynodon spp) e outro com o Capim Marandu (Brachiaria brizantha). Cada experimento foi montado no esquema em parcelas subdivididas $4 \times 3$ com cinco repetições. As parcelas de cada experimento corresponderam a quatro tratamentos fertirrigados com esgoto doméstico tratado (EDT) nas dosagens de 20, 40, 60 e $80 \mathrm{~kg} \mathrm{ha}^{-1}$ de nitrogênio e nas subparcelas três ciclos de produção, onde foram feitos cortes da parte aérea das forrageiras a cada 30 dias. Após cada corte do material vegetal das forrageiras, os tratamentos eram novamente aplicados.

O EDT utilizado no experimento foi coletado na estação de tratamento de esgoto doméstico do município de Jerônimo Monteiro e para caracterização química (Tabela 2) uma amostra de $200 \mathrm{~mL}$ foi coletada e encaminhada ao laboratório onde foram determinadas a condutividade elétrica, $\mathrm{pH}$, teores totais de nitrogênio, fósforo, potássio, cálcio, magnésio, sódio, ferro e boro conforme descrito pela Apha (1995).

Tabela 2. Caracterização química do esgoto doméstico tratado utilizado durante o experimento

\begin{tabular}{lc}
\hline Característica & Valor \\
\hline $\mathrm{pH}$ & 7,62 \\
Condutividade elétrica $\left(\mathrm{dS} \mathrm{m}{ }^{-1}\right)$ & 0,51 \\
Potássio $\left(\mathrm{mg} \mathrm{L}^{-1}\right)$ & 14,84 \\
Sódio $\left(\mathrm{mg} \mathrm{L}^{-1}\right)$ & 9,2 \\
Cloretos $\left(\mathrm{mg} \mathrm{L}^{-1}\right)$ & 3,72 \\
Ferro $\left(\mathrm{mg} \mathrm{L}^{-1}\right)$ & $<0,01$ \\
Fósforo Total $\left(\mathrm{mg} \mathrm{L}^{-1}\right)$ & 18,0 \\
Nitrogênio Total $\left(\mathrm{mg} \mathrm{L}^{-1}\right)$ & 57,0 \\
Cálcio $\left(\mathrm{mg} \mathrm{L}^{-1}\right)$ & 26,1 \\
Magnésio $\left(\mathrm{mg} \mathrm{L}^{-1}\right)$ & 24,1 \\
Enxofre $\left(\mathrm{mg} \mathrm{L}^{-1}\right)$ & 0,09 \\
Razão de Adsorção de Sódio $\left(\mathrm{cmol}_{\mathrm{c}} \mathrm{L}^{-1}\right)$ & 1,70 \\
\hline
\end{tabular}

O EDT foi coletado, transportado em recipientes de 60 litros e armazenado em um reservatório de 500 litros dentro da casa de vegetação, de onde foi retirado diretamente por meio de torneira e sua aplicação nas unidades experimentais foi feito manualmente com auxílio de uma proveta graduada com volume de um litro.

$O$ plantio das forrageiras ocorreu na primeira quinzena do mês de junho de 2010 quando as mudas de Tifton 85 e Capim Marandu foram transplantadas de forma a promover em cada unidade experimental, a mesma densidade de plantas. Após 15 dias do transplantio realizou-se um corte de uniformização em todas as parcelas.

Nos primeiros 30 dias após o plantio nos vasos, as forrageiras das unidades experimentais, foram irrigadas apenas com água obedecendo a um balanço hídrico no solo seguindo um turno de rega de três dias. O manejo da água nos experimentos foi feito por meio do método da pesagem dos vasos, onde a diferença de peso correspondia ao volume de água e, ou efluente a ser aplicada para elevar o solo à capacidade de campo.

Para o cálculo das doses de EDT, o teor de nitrogênio foi tomado como referência para se estabelecer as lâminas necessárias à aplicação das diferentes doses do elemento conforme descrito em cada arranjo experimental. Foi feita adubação química complementar, subtraindo-se dos valores de fósforo e potássio advindos das diferentes lâminas de efluente aplicadas em cada tratamento correspondente. A fertirrigação das forrageiras com EDT foi realizada após 30 dias do transplantio. A aplicação do esgoto doméstico tratado foi feita obedecendo a um turno de rega de três dias até completar o valor total aplicado em cada tratamento.

Transcorridos 30 dias após o término da aplicação do EDT, a massa verde das forrageiras, em casa vaso, foi cortada com o auxílio de uma tesoura. O corte foi efetuado a cinco centímetros de altura da superfície do solo no vaso e após esta etapa a massa verde foi acondicionada em sacos de papel 
previamente identificados e levada à estufa de circulação forçada de ar à temperatura de $65^{\circ} \mathrm{C} \pm 2$ durante $72 \mathrm{~h}$ para secagem e determinação da massa seca. Após cada corte foi realizada novamente a adubação mineral e aplicação do esgoto doméstico tratado seguindo as dosagens estabelecidas em cada parcela experimental, durante três ciclos.

O material seco foi triturado em moinho tipo Willey e acondicionado em recipiente de plástico devidamente identificado e encaminhando ao laboratório onde segundo a metodologia proposta pela Embrapa (2009) foram determinados os teores foliares de nitrogênio, fósforo, potássio, cálcio magnésio, enxofre e sódio. A capacidade de extração dos macronutrientes e sódio pelas plantas foi obtida pelo produto da concentração do nutriente no tecido foliar e a produtividade de massa seca.
A análise estatística das características avaliadas em cada experimento foi feita por meio de análise de variância, teste de média e regressão adotando $\alpha$ de até $5 \%$, considerando o esquema de parcelas subdivididas com os tratamentos fertirrigados com esgoto doméstico tratado nas parcelas e os cortes nas subparcelas.

\section{RESULTADOS E DISCUSSÃO}

A massa seca do Tifton 85 e do capim Marandu foi influenciada pela interação entre os tratamentos aplicados e os cortes $(\mathrm{p}<0,05)$. No teste de médias apresentado na Tabela 3, observa-se dentro de cada dose de EDT, o incremento na produção de biomassa do Tifton 85 ocorreu no $2^{\circ}$ corte, o mesmo não ocorrendo para o Capim Marandú que decresceu com os cortes efetuados.

Tabela 3. Valores da massa seca no Tifton 85 e Capim Marandú nos três cortes realizados em função doses de nitrogênio aplicado por meio do esgoto doméstico tratado com base na recomendação para as forrageiras

\begin{tabular}{|c|c|c|c|c|c|c|}
\hline \multirow{3}{*}{ Doses } & \multicolumn{3}{|c|}{ Capim Tifton 85} & \multicolumn{3}{|c|}{ Capim Marandú } \\
\hline & \multicolumn{3}{|c|}{ Cortes } & \multicolumn{3}{|c|}{ Cortes } \\
\hline & $1^{\circ}$ & $2^{\circ}$ & $3^{\circ}$ & $1^{\circ}$ & $2^{\circ}$ & $3^{\circ}$ \\
\hline & \multicolumn{6}{|c|}{-------------------------------- Massa Seca $\left(\mathrm{kg} \mathrm{ha}^{-1}\right)$-------------------------- } \\
\hline 20 & $929,72 \mathrm{~b}$ & $1237,50 \mathrm{a}$ & $624,17 \mathrm{c}$ & $431,67 \mathrm{~b}$ & 547,5 a & $340,56 \mathrm{c}$ \\
\hline 40 & $1065,83 \mathrm{~b}$ & $1352,78 \mathrm{a}$ & $790,83 \mathrm{c}$ & $975,83 \mathrm{~b}$ & $1070,01 \mathrm{a}$ & $585,83 \mathrm{c}$ \\
\hline 60 & $1417,77 \mathrm{~b}$ & $2207,22 \mathrm{a}$ & $1039,44 \mathrm{c}$ & $1636,9 \mathrm{~b}$ & $1261,11 \mathrm{a}$ & $784,44 \mathrm{c}$ \\
\hline 80 & $1413,05 \mathrm{~b}$ & $2256,67 \mathrm{a}$ & $1040,00 \mathrm{c}$ & $1795,8 \mathrm{~b}$ & $1476,91 \mathrm{a}$ & $894,72 \mathrm{c}$ \\
\hline
\end{tabular}

Médias seguidas pela mesma letra minúsculas nas linhas dentro de cada forrageira, não diferem entre si pelo teste de Tuckey $(\mathrm{P}<0,05)$.

O decréscimo de massa seca do Capim Marandú e do Tifton no terceiro corte estão relacionados ao aumento do perfilhamento e da densidade de plantas nas condições experimentais. Dessa forma, apesar das plantas expressarem seus potenciais de crescimento com a aplicação do EDT, a competição por luz e nutrientes, dentro da unidade experimental, tornou-se maior com o aumento no número de cortes, resultando no decréscimo desta característica. Resultado semelhante foi observado por Premazzi et al. $(2003,2011)$ para o Tifton 85. Do mesmo modo Bennet et al. (2008) descreveram que a produção de biomassa em Brachiaria brizantha diminuiu no segundo e terceiro corte quando aplicados, respectivamente, 179 e $141 \mathrm{~kg} \mathrm{ha}^{-}$ ${ }^{1}$ de nitrogênio.

O desdobramento do efeito dos cortes das forrageiras em decorrência das doses de EDT apresentou aumento linear positivo da massa seca no Tifton 85 e Capim Marandu (Figura 1 e Tabela
4). Nesse sentido, o aumento na produção de biomassa é desejável para a manutenção e produção da pecuária, pois os alimentos volumosos são as fontes mais baratas de energia, proteína e de minerais.

Estes resultados estão relacionados com o aporte de nutrientes, principalmente nitrogênio e fósforo, propiciado pelo aumento das doses de EDT uma vez que a baixa fertilidade natural dos solos nas condições naturais das pastagens no Brasil desfavorece diretamente a produtividade das forragens. Estes resultados estão coerentes com os relatados para o Tifton 85 fertirrigado com água residuária da bovinocultura (ERTHAL et al., 2010), esgoto doméstico tratado (FONSECA et al., 2007; BELTRÃO et al., 2008); Panicum maximum cv. Tanzânia e Moçamba fertirrigado com efluente da carcinocultura (MIRANDA et al., 2010) e Capim Elefante fertirrigado com água residuária da suinocultura (CABRAL et al., 2011). 


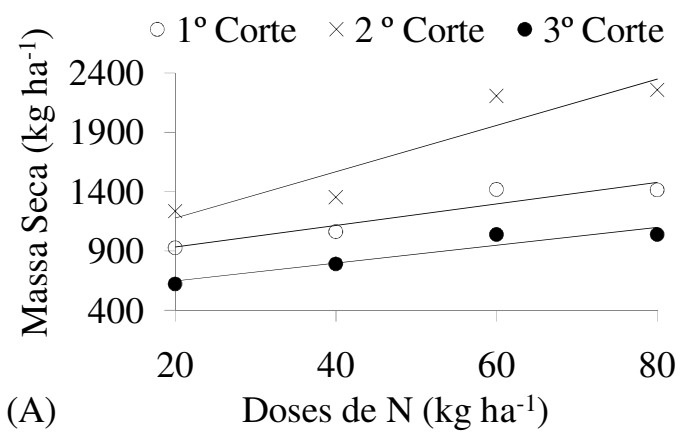

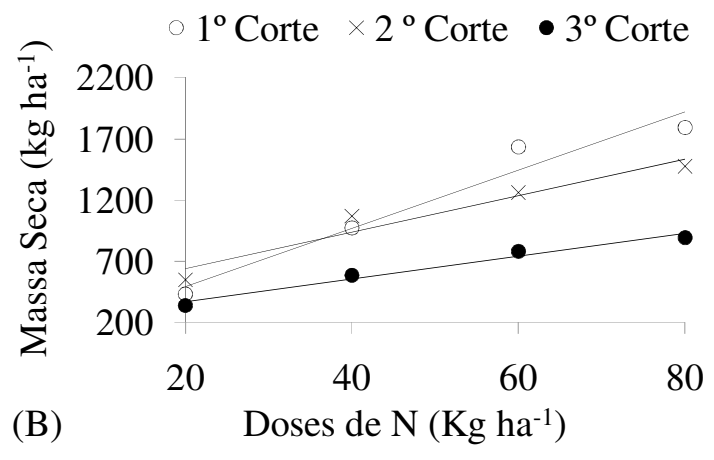

Figura1. Massa seca das forrageiras Tifton 85 (A) e Capim Marandú (B) em função das doses de nitrogênio aplicado por meio do esgoto doméstico tratado com base na recomendação para as forrageiras.

Tabela 4. Equações ajustadas relacionando-se a massa seca no Tifton 85 e Capim Marandú função doses de nitrogênio aplicado por meio do esgoto doméstico tratado nos três cortes realizados

\begin{tabular}{|c|c|c|c|c|}
\hline \multirow[b]{2}{*}{ Cortes } & \multicolumn{2}{|l|}{ Capim Tifton 85} & \multicolumn{2}{|l|}{ Capim Marandú } \\
\hline & Equação & $\mathrm{r}^{2}$ & Equação & $\mathrm{r}^{2}$ \\
\hline $1^{\circ}$ & $\hat{y}=756,11+9,01^{*}$ Doses & 0,8834 & $\hat{y}=201,66+23,76^{*}$ Doses & 0,9524 \\
\hline $2^{\circ}$ & $\hat{\mathrm{y}}=758,56+19,56^{*}$ Doses & 0,8643 & $\hat{y}=344,03+14,89^{*}$ Doses & 0,9377 \\
\hline $3^{\circ}$ & $\hat{y}=499,58+7,48^{*}$ Doses & 0,9001 & $\hat{\mathrm{y}}=186,11+9,04^{*}$ Doses & 0,9733 \\
\hline
\end{tabular}

$*$ Significativo a $5 \%$ de probabilidade.

A extração de macronutrientes e sódio do solo pelas forrageiras Tifton 85 e Capim Marandú foi influenciada pela interação dos tratamentos fertirrigados e os ciclos de produção $(\mathrm{p}<0,05)$. Desta forma observa-se na Tabela 5 que no cultivo do Tifton 85 , dentro de cada dose de nitrogênio aplicada por meio do EDT, a extração de sódio, nitrogênio e cálcio foram maiores no primeiro e segundo corte. Já a extração de potássio, enxofre e magnésio aumentaram no segundo corte. Enquanto que na extração do fósforo não houve diferença significativa entre os cortes. Por sua vez, no cultivo do Capim Marandú, dentro de cada dose de nitrogênio aplicada por meio do EDT, a extração dos nutrientes foi maior no primeiro corte decrescendo nos cortes subsequentes. Estes resultados evidenciam que as extrações de nutrientes pelo Tifton 85 e Capim Marandú no presente estudo estão correlacionadas com a produção de biomassa no ciclo de produção. Para o segundo ciclo de produção do Tifton 85 e o primeiro no Capim Marandú, os períodos nos quais ocorreram maiores valores de massa seca (Tabela 3), as forrageiras exigiram maiores quantidades de nutrientes para obter sua produção.

Tabela 5. Valores médios das quantidades de nutrientes extraídos do solo pelo Tifton 85 e Capim Marandú nos três ciclos de produção dentro de cada doses de nitrogênio aplicado por meio do esgoto doméstico tratado

\begin{tabular}{|c|c|c|c|c|c|c|c|c|}
\hline \multirow{3}{*}{ Corte } & \multicolumn{4}{|c|}{ Doses de Nitrogênio $\left(\mathrm{kg} \mathrm{ha}^{-1}\right)$} & \multicolumn{4}{|c|}{ Doses de Nitrogênio $\left(\mathrm{kg} \mathrm{ha}^{-1}\right)$} \\
\hline & 20 & 40 & 60 & 80 & 20 & 40 & 60 & 80 \\
\hline & \multicolumn{8}{|c|}{ Extração de Nitrogênio $\left(\mathrm{kg} \mathrm{ha}^{-1}\right)$} \\
\hline $1^{\circ}$ & $7,08 \mathrm{a}$ & $7,64 \mathrm{a}$ & $13,82 \mathrm{a}$ & $18,38 \mathrm{a}$ & $8,02 \mathrm{a}$ & $9,65 \mathrm{a}$ & $11,17 \mathrm{a}$ & $16,46 \mathrm{a}$ \\
\hline $2^{\circ}$ & $8,29 \mathrm{a}$ & $7,92 \mathrm{a}$ & $15,38 \mathrm{a}$ & $17,22 \mathrm{a}$ & $3,35 \mathrm{~b}$ & $6,63 \mathrm{~b}$ & $9,08 \mathrm{~b}$ & $10,18 \mathrm{~b}$ \\
\hline $3^{\circ}$ & $4,23 \mathrm{~b}$ & $5,53 \mathrm{~b}$ & $7,98 \mathrm{~b}$ & $9,97 \mathrm{~b}$ & $2,71 \mathrm{c}$ & $5,27 \mathrm{c}$ & $7,11 \mathrm{c}$ & $8,13 \mathrm{c}$ \\
\hline \multicolumn{9}{|c|}{ Extração de Potássio $\left(\mathrm{kg} \mathrm{ha}^{-1}\right)$} \\
\hline $1^{\circ}$ & $9,32 \mathrm{~b}$ & $11,18 b$ & $12,70 \mathrm{~b}$ & $14,72 \mathrm{~b}$ & $17,51 \mathrm{a}$ & $20,38 \mathrm{a}$ & $23,81 \mathrm{a}$ & $26,86 \mathrm{a}$ \\
\hline $2^{\circ}$ & $15,01 \mathrm{a}$ & $16,81 \mathrm{a}$ & $24,67 \mathrm{a}$ & $24,01 \mathrm{a}$ & $9,07 \mathrm{~b}$ & $18,69 \mathrm{~b}$ & $16,94 \mathrm{~b}$ & $22,50 \mathrm{~b}$ \\
\hline $3^{\circ}$ & $8,45 \mathrm{~b}$ & $10,83 \mathrm{~b}$ & $13,39 \mathrm{~b}$ & $14,53 \mathrm{~b}$ & $5,59 \mathrm{c}$ & $10,15 \mathrm{c}$ & $13,97 \mathrm{c}$ & $15,89 \mathrm{c}$ \\
\hline
\end{tabular}




\begin{tabular}{|c|c|c|c|c|c|c|c|c|}
\hline $1^{\circ}$ & $2,36 \mathrm{a}$ & $2,54 \mathrm{a}$ & $2,63 \mathrm{a}$ & $3,54 \mathrm{a}$ & $1,54 \mathrm{a}$ & $1,58 \mathrm{a}$ & $1,87 \mathrm{a}$ & $1,99 \mathrm{a}$ \\
\hline $2^{\circ}$ & $1,39 \mathrm{~b}$ & $1,42 \mathrm{~b}$ & $1,99 \mathrm{~b}$ & $2,53 \mathrm{~b}$ & $0,21 \mathrm{~b}$ & $0,32 \mathrm{~b}$ & $0,79 \mathrm{~b}$ & $0,91 \mathrm{~b}$ \\
\hline $3^{\circ}$ & $1,14 \mathrm{~b}$ & $1,56 \mathrm{~b}$ & $1,94 \mathrm{~b}$ & $2,74 \mathrm{~b}$ & $0,18 \mathrm{c}$ & $0,58 \mathrm{c}$ & $0,69 \mathrm{c}$ & $0,86 \mathrm{c}$ \\
\hline \multicolumn{9}{|c|}{ Extração de Fósforo $\left(\mathrm{kg} \mathrm{ha}^{-1}\right)$} \\
\hline $1^{\circ}$ & $1,44 \mathrm{a}$ & $1,53 \mathrm{a}$ & $1,72 \mathrm{a}$ & $1,96 \mathrm{a}$ & $1,88 \mathrm{a}$ & $1,95 \mathrm{a}$ & $2,04 \mathrm{a}$ & $2,44 \mathrm{a}$ \\
\hline $2^{\circ}$ & $1,13 \mathrm{a}$ & $1,88 \mathrm{a}$ & $2,58 \mathrm{a}$ & $2,68 \mathrm{a}$ & $0,91 \mathrm{~b}$ & $1,42 \mathrm{~b}$ & $2,01 \mathrm{~b}$ & $2,06 \mathrm{~b}$ \\
\hline $3^{\circ}$ & $1,29 \mathrm{a}$ & $1,36 \mathrm{a}$ & $1,47 \mathrm{a}$ & $1,55 \mathrm{a}$ & $0,90 \mathrm{~b}$ & $1,42 \mathrm{~b}$ & $1,82 \mathrm{~b}$ & $2,05 \mathrm{~b}$ \\
\hline \multicolumn{9}{|c|}{ Extração de Cálcio $\left(\mathrm{kg} \mathrm{ha}^{-1}\right)$} \\
\hline $1^{\circ}$ & $6,41 \mathrm{a}$ & $6,95 \mathrm{a}$ & $7,99 \mathrm{a}$ & $8,67 \mathrm{a}$ & $3,45 \mathrm{a}$ & $3,75 \mathrm{a}$ & $3,73 \mathrm{a}$ & $3,86 \mathrm{a}$ \\
\hline $2^{\circ}$ & $6,79 \mathrm{a}$ & $6,87 \mathrm{a}$ & $9,43 \mathrm{a}$ & 9,98 a & $1,02 \mathrm{~b}$ & $2,33 \mathrm{~b}$ & $2,42 \mathrm{~b}$ & $3,27 \mathrm{~b}$ \\
\hline $3^{\circ}$ & $1,71 \mathrm{~b}$ & $1,86 \mathrm{~b}$ & $2,64 \mathrm{~b}$ & $2,74 \mathrm{~b}$ & $1,05 \mathrm{~b}$ & $1,88 \mathrm{~b}$ & $2,83 \mathrm{~b}$ & $3,29 \mathrm{~b}$ \\
\hline \multicolumn{9}{|c|}{ Extração de Enxofre $\left(\mathrm{kg} \mathrm{ha}^{-1}\right)$} \\
\hline $1^{\circ}$ & $2,37 \mathrm{~b}$ & $2,77 \mathrm{~b}$ & $3,72 \mathrm{~b}$ & $3,90 \mathrm{~b}$ & $1,41 \mathrm{a}$ & $1,61 \mathrm{a}$ & $1,66 \mathrm{a}$ & $2,04 \mathrm{a}$ \\
\hline $2^{\circ}$ & $3,79 \mathrm{a}$ & $4,17 \mathrm{a}$ & $6,54 \mathrm{a}$ & $6,63 \mathrm{a}$ & $0,54 \mathrm{~b}$ & $0,98 \mathrm{~b}$ & $1,39 \mathrm{~b}$ & $1,83 \mathrm{~b}$ \\
\hline $3^{\circ}$ & $2,64 \mathrm{~b}$ & $3,13 \mathrm{~b}$ & $3,88 \mathrm{~b}$ & $4,06 \mathrm{~b}$ & $0,71 \mathrm{~b}$ & $1,26 \mathrm{~b}$ & $1,43 \mathrm{~b}$ & $1,98 \mathrm{~b}$ \\
\hline \multicolumn{9}{|c|}{ Extração de Magnésio $\left(\mathrm{kg} \mathrm{ha}^{-1}\right)$} \\
\hline $1^{\circ}$ & $2,49 \mathrm{~b}$ & $2,50 \mathrm{~b}$ & $3,60 \mathrm{~b}$ & $4,16 \mathrm{~b}$ & $4,28 \mathrm{a}$ & $5,13 \mathrm{a}$ & $5,61 \mathrm{a}$ & $7,00 \mathrm{a}$ \\
\hline $2^{\circ}$ & $2,87 \mathrm{a}$ & $3,28 \mathrm{a}$ & $6,05 \mathrm{a}$ & $6,28 \mathrm{a}$ & $1,56 \mathrm{~b}$ & $3,43 \mathrm{~b}$ & $4,43 \mathrm{~b}$ & $5,76 \mathrm{~b}$ \\
\hline $3^{\circ}$ & $1,53 \mathrm{c}$ & $1,84 \mathrm{c}$ & $2,96 \mathrm{c}$ & $3,07 \mathrm{c}$ & $1,82 \mathrm{~b}$ & $2,91 \mathrm{~b}$ & $4,28 \mathrm{~b}$ & $5,52 \mathrm{~b}$ \\
\hline
\end{tabular}

Embora a literatura destacar que as forrageiras, de modo geral, apresentam elevados índices de extração de nutrientes do solo, nas condições em que o presente trabalho foi desenvolvido, não foram observadas elevadas extrações de nutrientes pelas espécies estudadas. Nesse sentido, estudos com Tifton 85 conduzidos por Erthal et al. (2010), Matos et al. (2010) e Queiroz et al. (2004) e com Capim Marandú (COSTA et al., 2010), Primavesi et al. (2006) e Braz et al. (2004) encontraram valores de extração de nutrientes superiores aos do presente estudo. Esses resultados não demonstram a impossibilidade do uso do EDT na fertirrigação de pastagens, pois as doses de nitrogênio aplicados por meio do EDT foram inferiores aos estudos apresentados.

Observa-se também na Tabela 4 que, nas duas forrageiras estudadas, o potássio foi o nutriente extraído em maior quantidade dentro de todas as doses de nitrogênio aplicadas por meio do EDT e resultados semelhantes foram encontrados por Costa et al. (2010) e Primavesi et al. (2006) em Brachiaria brizantha e Primavesi et al. (2004) no capimcoastcross. Em diversas plantas o potássio é absorvido em quantidades superiores às necessárias (MEURER, 2006), logo o aumento do teor deste nutriente na planta promove uma maior taxa de absorção de nitrato e pode inibir as de cálcio e magnésio (MARSCHNER, 1995). Sabe-se que também que o potássio atua na manutenção da quantidade de água nas plantas devido à regulação osmótica das células e estudos conduzidos por
Santos et al. (2006) e Miranda et al. (2010) demostram que a salinidade do solo eleva-se com a aplicação do esgoto doméstico acarretando na diminuição da disponibilidade de água para as plantas devido ao decréscimo do potencial osmótico da solução do solo. Nesse sentido não foram observadas sintomas de deficiência hídrica nas plantas, ou seja, a absorção de água pelas forrageiras foi mantida pela absorção ativa do potássio.

Por outro lado, observa-se na Tabela 5 que o sódio foi extraído em menor quantidade nas duas forrageiras. Esse resultado demonstra que em períodos curtos a aplicação de EDT, não proporciona elevações dos níveis de sódio nas plantas, consequentemente os distúrbios fisiológicos decorrentes da acumulação deste íon não comprometerá o desenvolvimento das mesmas. No entanto, segundo Queiroz et al. (2004) a elevada capacidade de extração de sódio é uma característica desejável nas forrageiras pois estas podem auxiliar no controle de possíveis problemas de salinização e sodificação do solo.

Observa-se nas Figuras 2 e 3 e nas Tabelas 6 e 7 que a extração dos macronutrientes e do sódio pelo Tifton 85 e Capim Marandú em função das doses de nitrogênio aplicadas por meio do EDT nos três cortes realizados aumentaram linearmente atingindo maiores valores, em cada corte, quando aplicada a dose de $80 \mathrm{~kg} \mathrm{ha}^{-1}$. Este resultado indica que a utilização do EDT por meio da técnica da fertirrigação, contribui para a melhoria da fertilidade 
Massa seca e extração de nutrientes...

do solo devido ao aporte de nutrientes advindos pelo mesmo.
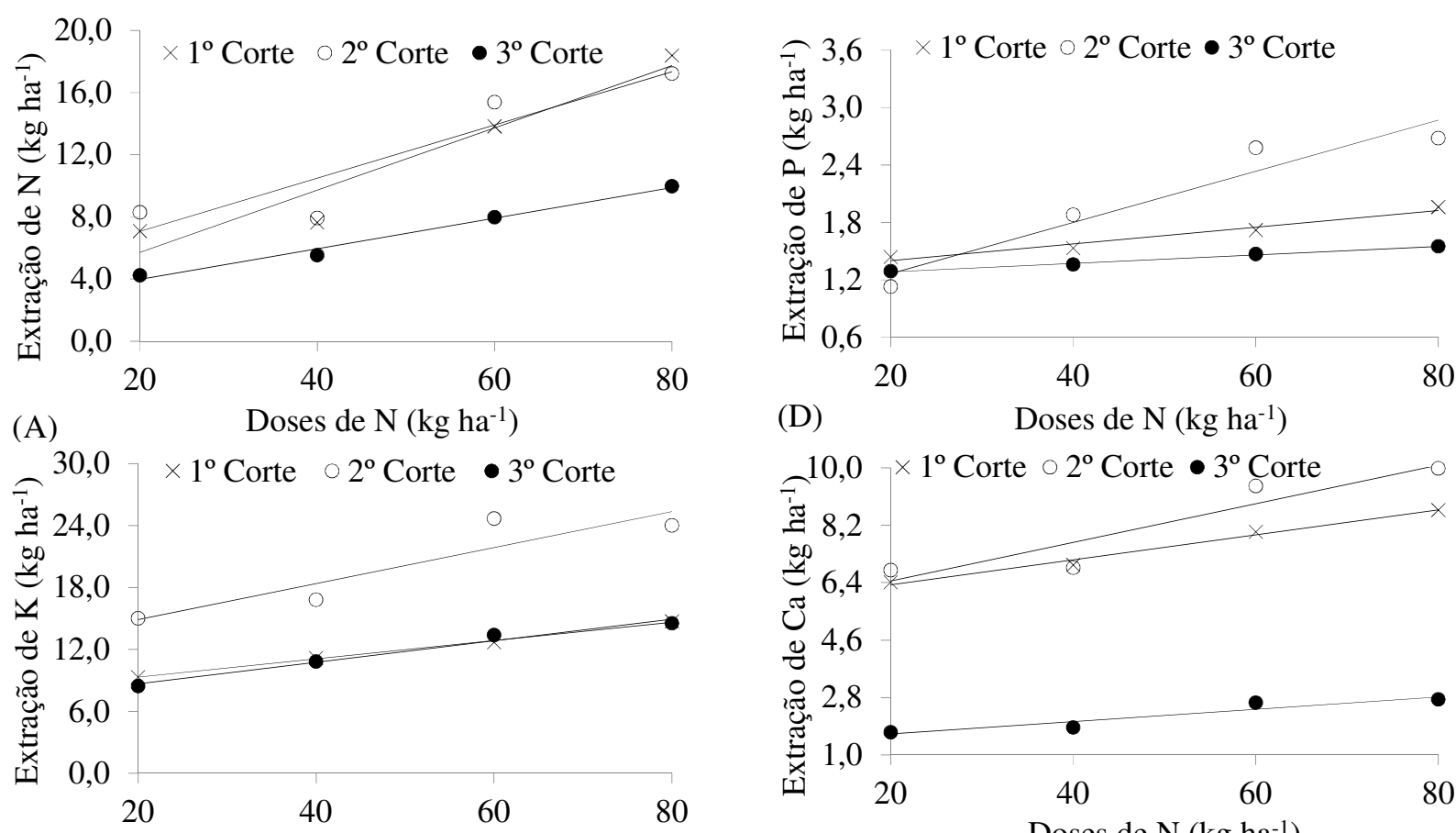

(D) Doses de $\mathrm{N}\left(\mathrm{kg} \mathrm{ha}^{-1}\right)$
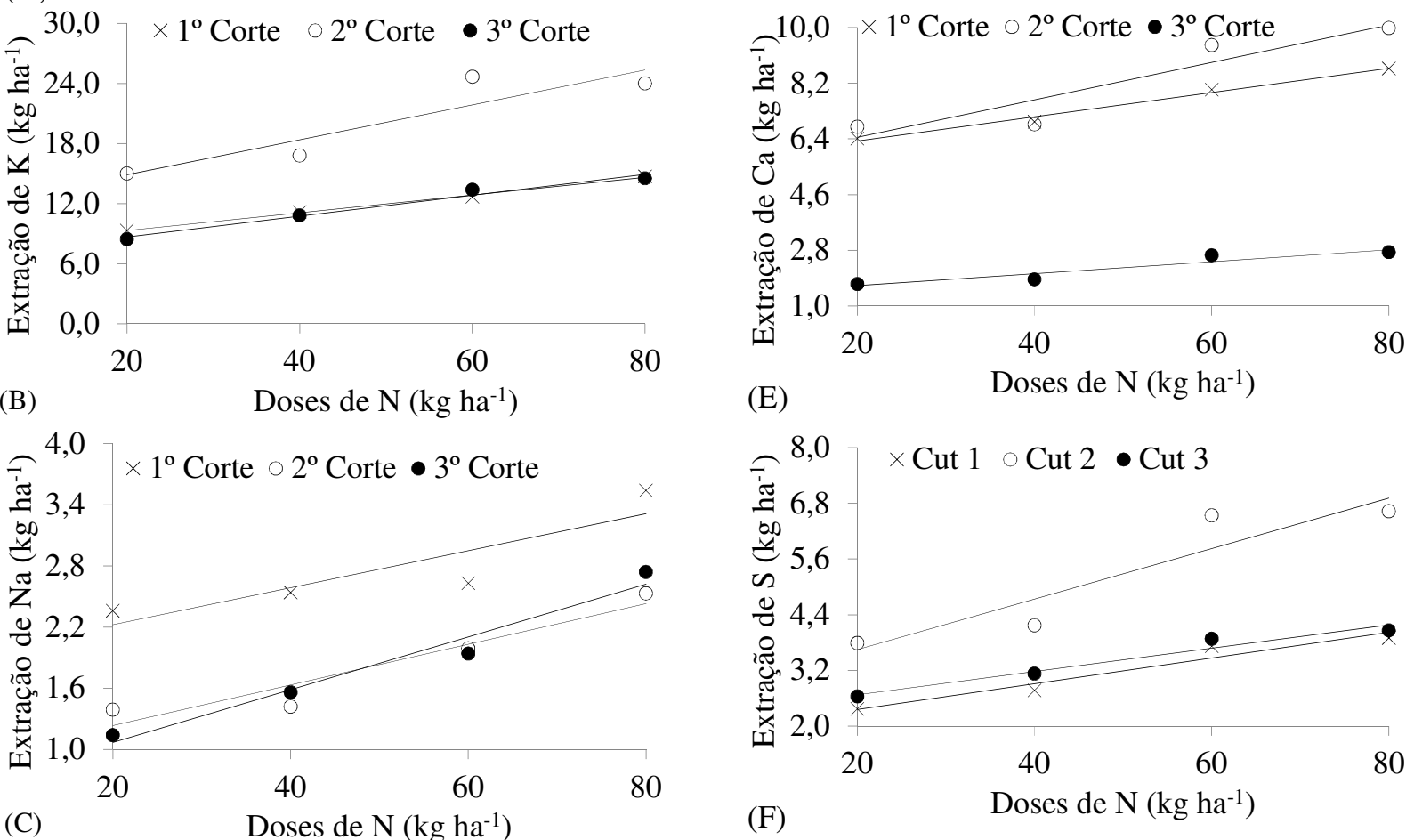

(E) Doses de $\mathrm{N}\left(\mathrm{kg} \mathrm{ha}^{-1}\right)$
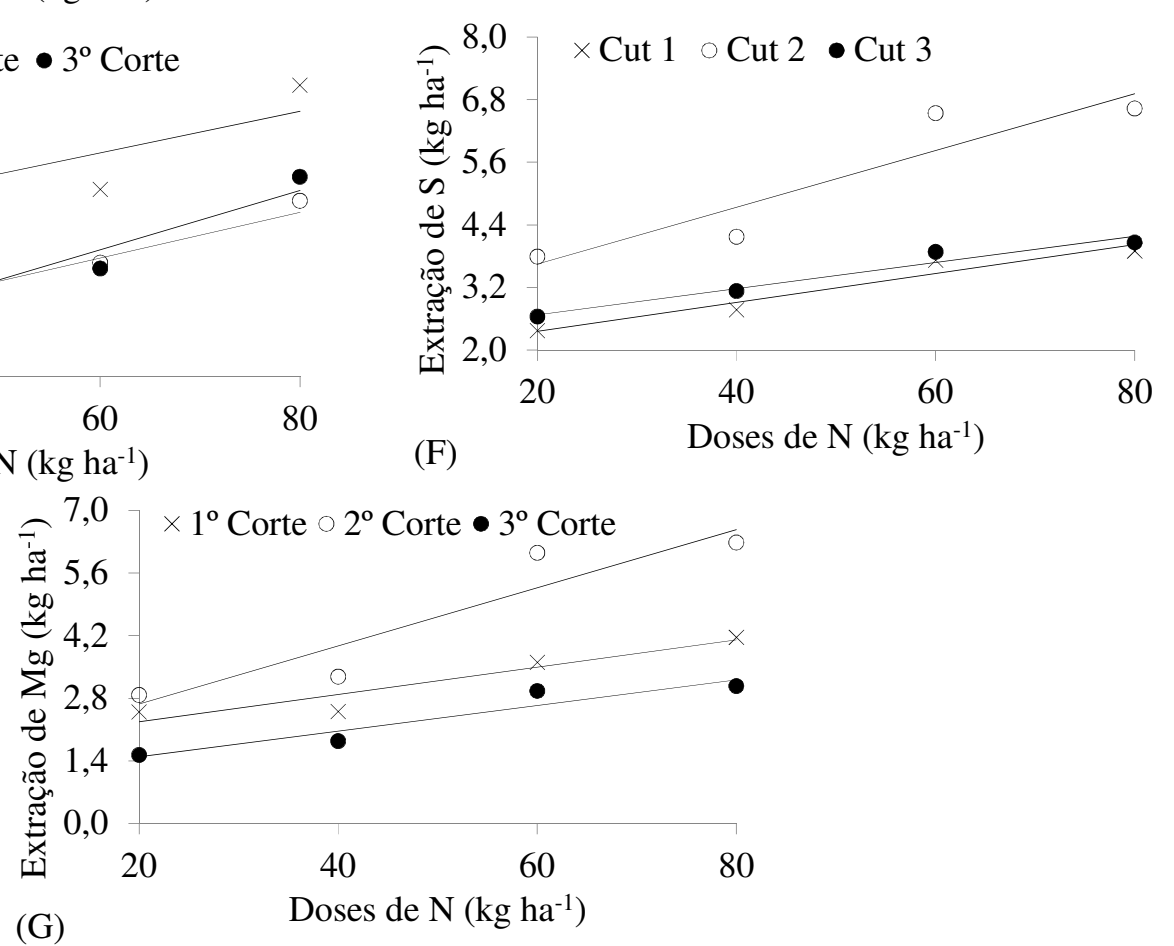

Figura 2. Teores de nitrogênio (A), potássio (B), sódio (C), fósforo (D), cálcio (E), enxofre (F) e magnésio $(\mathrm{G})$ na forrageira Tifton 85 nos três ciclos de produção em função das doses de nitrogênio aplicado por meio do esgoto doméstico tratado. 

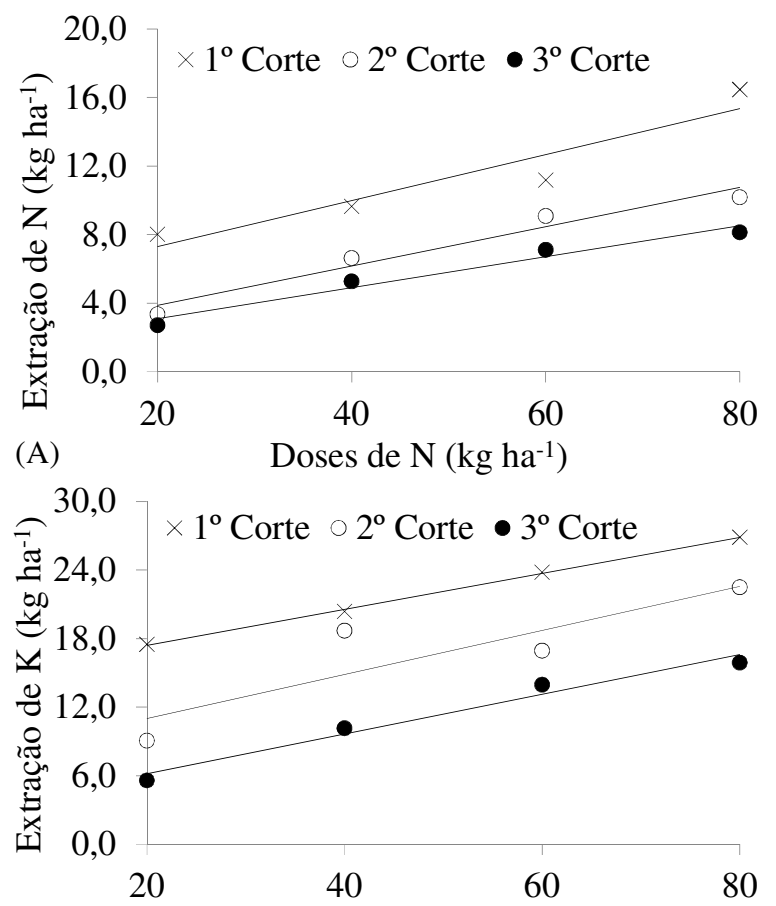

(B)

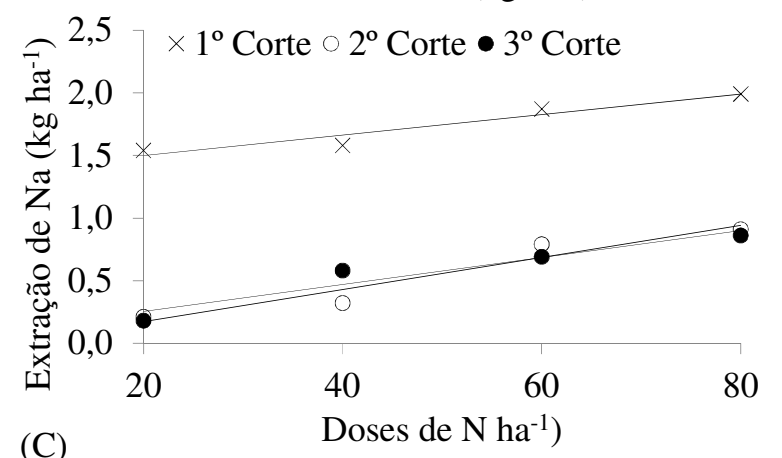

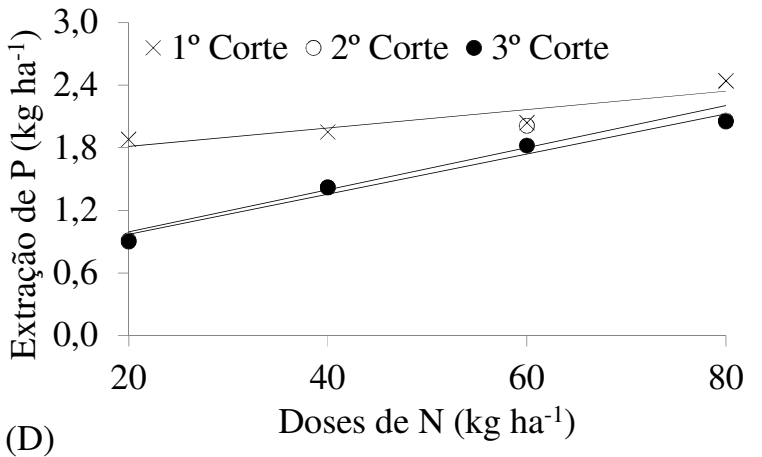

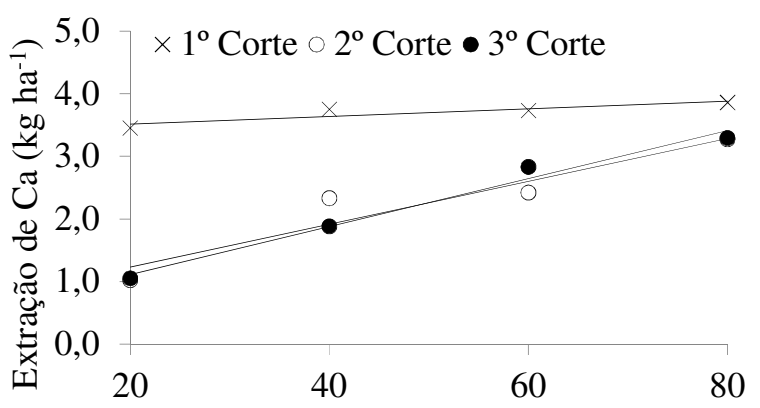

(E) Doses de $\mathrm{N}\left(\mathrm{kg} \mathrm{ha}^{-1}\right)$

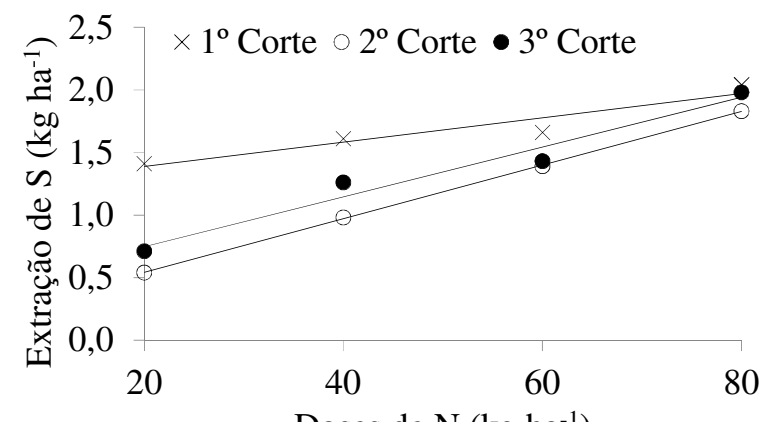

(F)

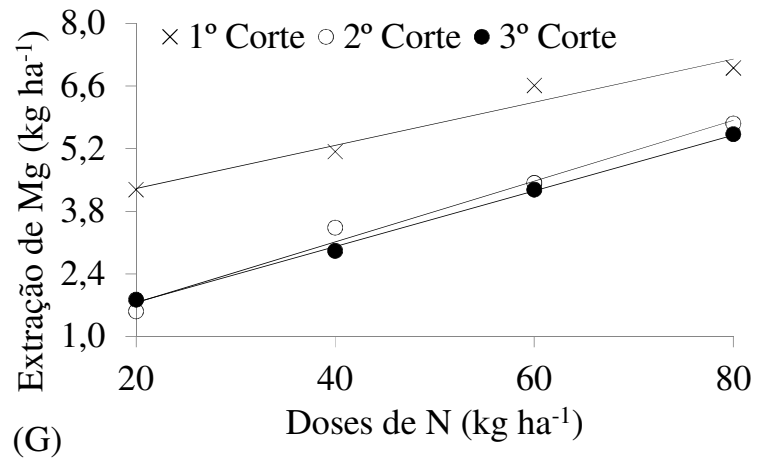

Figura 3. Teores de nitrogênio (A), potássio (B), sódio (C), fósforo (D), cálcio (E), enxofre (F) e magnésio (G) no Capim Marandu nos três ciclos de produção em função das doses de nitrogênio aplicado por meio do esgoto doméstico tratado. 
Tabela 6. Equações ajustadas e coeficiente de determinação $\left(\mathrm{r}^{2}\right)$ para as curvas de extração de macronutrientes e sódio do solo pela forrageira Tifton 85 nos três ciclos de produção em função das doses de nitrogênio aplicado por meio do esgoto doméstico tratado

\begin{tabular}{|c|c|c|c|}
\hline \multirow[b]{2}{*}{ Nutriente } & \multirow[t]{2}{*}{ Corte } & \multicolumn{2}{|l|}{ Tifton 85} \\
\hline & & Equação & $\mathrm{r}^{2}$ \\
\hline \multirow{3}{*}{ Nitrogênio } & $1^{\circ}$ & $\hat{\mathrm{y}}=1,7182+0,2004^{* *} \times$ Dose de $N$ & 0,9238 \\
\hline & $2^{\circ}$ & $\hat{y}=3,6431+0,1713^{* *} \times$ Dose de N & 0,8523 \\
\hline & $3^{\circ}$ & $\hat{y}=2,0124+0,0984^{* *} \times$ Dose de N & 0,9873 \\
\hline \multirow{3}{*}{ Potássio } & $1^{\circ}$ & $\hat{\mathrm{y}}=7,5353+0,0886^{* *} \times$ Dose de $\mathrm{N}$ & 0,9974 \\
\hline & $2^{o}$ & $\hat{y}=11,4184+0,1743^{* *} \times$ Dose de N & 0,8335 \\
\hline & $3^{\mathrm{o}}$ & $\hat{\mathrm{y}}=6,6623+0,1041^{* *} \times$ Dose de $\mathrm{N}$ & 0,9769 \\
\hline \multirow{3}{*}{ Sódio } & $1^{\circ}$ & $\hat{\mathrm{y}}=1,8638+0,0182^{* *} \times$ Dose de $\mathrm{N}$ & 0,7905 \\
\hline & $2^{\circ}$ & $\hat{y}=0,8351+0,0211^{* * *} \times$ Dose de N & 0,9074 \\
\hline & $3^{\circ}$ & $\hat{y}=0,5525+0,0259^{* *} \times$ Dose de N & 0,9664 \\
\hline \multirow{3}{*}{ Fósforo } & $1^{\circ}$ & $\hat{\mathrm{y}}=1,2251+0,0081^{* *} \times$ Dose de $\mathrm{N}$ & 0,9636 \\
\hline & $2^{\circ}$ & $\hat{y}=0,7373+0,0262^{* *} \times$ Dose de N & 0,9636 \\
\hline & $3^{\circ}$ & $\hat{y}=1,1951+0,0042^{* *} \times$ Dose de N & 0,9931 \\
\hline \multirow{3}{*}{ Cálcio } & $1^{\circ}$ & $\hat{\mathrm{y}}=5,5582+0,0391^{* *} \times$ Dose de $N$ & 0,9861 \\
\hline & $2^{o}$ & $\hat{y}=5,2355+0,0601^{* * *} \times$ Dose de N & 0,8733 \\
\hline & $3^{\circ}$ & $\hat{\mathrm{y}}=1,2733+0,0191^{* *} \times$ Dose de N & 0,8966 \\
\hline \multirow{3}{*}{ Enxofre } & $1^{\circ}$ & $\hat{\mathrm{y}}=1,8051+0,0271^{* * *} \times$ Dose de $\mathrm{N}$ & 0,9392 \\
\hline & $2^{\circ}$ & $\hat{y}=2,5643+0,0544^{* *} \times$ Dose de N & 0,8641 \\
\hline & $3^{\circ}$ & $\hat{y}=2,1752+0,0252^{* *} \times$ Dose de N & 0,9555 \\
\hline \multirow{3}{*}{ Magnésio } & $1^{\circ}$ & $\hat{\mathrm{y}}=1,6646+0,0313^{* *} \times$ Dose de $\mathrm{N}$ & 0,8992 \\
\hline & $2^{\circ}$ & $\hat{y}=1,3736+0,0652^{* *} \times$ Dose de N & 0,8741 \\
\hline & $3^{\circ}$ & $\hat{y}=0,9152+0,0283^{* *} \times$ Dose de $N$ & 0,9032 \\
\hline
\end{tabular}

** Significativo a $1 \%$ de probabilidade.

Tabela 7. Equações ajustadas e coeficiente de determinação $\left(r^{2}\right)$ para as curvas de extração de macronutrientes e sódio do solo pelo Capim Marandu nos três ciclos de produção em função das doses de nitrogênio aplicado por meio do esgoto doméstico tratado

\begin{tabular}{|c|c|c|c|}
\hline \multirow[b]{2}{*}{ Nutriente } & \multirow[t]{2}{*}{ Corte } & \multicolumn{2}{|l|}{ Capim Marandu } \\
\hline & & Equação & $\mathrm{r}^{2}$ \\
\hline \multirow{3}{*}{ Nitrogênio } & $1^{\circ}$ & $\hat{y}=4,6151+0,1344^{* *} \times$ Dose de $N$ & 0,8977 \\
\hline & $2^{\circ}$ & $\hat{\mathrm{y}}=1,5715+0,1114^{* *} \times$ Dose de $\mathrm{N}$ & 0,9562 \\
\hline & $3^{\circ}$ & $\hat{\mathrm{y}}=1,2828+0,0993^{* *} \times$ Dose de $\mathrm{N}$ & 0,9668 \\
\hline \multirow{3}{*}{ Potássio } & $1^{\circ}$ & $\hat{\mathrm{y}}=14,2786+0,1574^{* *} \times$ Dose de $N$ & 0,9989 \\
\hline & $2^{o}$ & $\hat{y}=7,1656+0,1927^{* *} \times$ Dose de $N$ & 0,7749 \\
\hline & $3^{\circ}$ & $\hat{\mathrm{y}}=2,7213+0,1736^{* *} \times$ Dose de $\mathrm{N}$ & 0,9709 \\
\hline \multirow{3}{*}{ Sódio } & $1^{\circ}$ & $\hat{\mathrm{y}}=1,3335+0,0082^{* *} \times$ Dose de $\mathrm{N}$ & 0,9281 \\
\hline & $2^{o}$ & $\hat{y}=0,0852+0,0129^{* *} \times$ Dose de $N$ & 0,9291 \\
\hline & $3^{\circ}$ & $\hat{\mathrm{y}}=0,0404+0,0108^{* *} \times$ Dose de $\mathrm{N}$ & 0,9227 \\
\hline \multirow{3}{*}{ Fósforo } & $1^{\circ}$ & $\hat{\mathrm{y}}=1,6355+0,0081^{* *} \times$ Dose de $\mathrm{N}$ & 0,8321 \\
\hline & $2^{o}$ & $\hat{y}=0,5983+0,0201^{* *} \times$ Dose de N & 0,9188 \\
\hline & $3^{\circ}$ & $\hat{y}=0,5853+0,0199^{* *} \times$ Dose de $N$ & 0,9722 \\
\hline \multirow{3}{*}{ Cálcio } & $1^{\circ}$ & $\hat{y}=1,1956+0,0092^{* *} \times$ Dose de N & 0,8001 \\
\hline & $2^{o}$ & $\hat{y}=0,5538+0,0344^{* *} \times$ Dose de N & 0,9031 \\
\hline & $3^{\circ}$ & $\hat{y}=0,3456+0,0386^{* *} \times$ Dose de N & 0,9821 \\
\hline
\end{tabular}




\begin{tabular}{llll}
\hline \multirow{3}{*}{ Enxofre } & $1^{\mathrm{o}}$ & $\hat{\mathrm{y}}=1,1956+0,5692^{* * *} \times$ Dose de N & 0,9051 \\
& $2^{\mathrm{o}}$ & $\hat{\mathrm{y}}=0,1152+0,0211^{* *} \times$ Dose de N & 0,9991 \\
& $3^{\mathrm{o}}$ & $\hat{\mathrm{y}}=0,3584+0,0191^{* *} \times$ Dose de N & 0,9644 \\
\hline \multirow{3}{*}{ Magnésio } & $1^{\mathrm{o}}$ & $\hat{\mathrm{y}}=3,3456+0,0482^{* *} \times$ Dose de N & 0,9888 \\
& $2^{\mathrm{o}}$ & $\hat{\mathrm{y}}=0,3956+0,0682^{* *} \times$ Dose de N & 0,9841 \\
& $3^{\mathrm{o}}$ & $\hat{\mathrm{y}}=0,5155+0,0623^{* *} \times$ Dose de N & 0,9988 \\
\hline
\end{tabular}

** Significativo a $1 \%$ de probabilidade

A fertilidade do solo tem relação direta no crescimento, produtividade e concentração de nutrientes nos tecidos foliares das plantas. Além disto, e se considerando que o EDT utilizado no experimento é um subproduto de interesse agronômico e que apresentou possibilidades reais de uso no cultivo agrícola, o mesmo pode ser utilizado como fertilizante promovendo um destino adequado a este subproduto, além das vantagens de redução de custo. Para sua utilização deve ser respeitada a dose adequada à fertilidade de cada tipo de solo e profundidade do lençol freático, tal como as das diretrizes técnicas fundamentadas nas exigências nutricionais da cultura instalada.

\section{CONCLUSÕES}

A produção de massa seca e a extração dos macronutrientes e sódio no Tifton 85 e no Capim Marandú aumentaram com o incremento das doses de nitrogênio aplicadas por meio do EDT;

O potássio e o sódio foram os nutrientes extraídos em maior e menor quantidade, respectivamente, pelas duas forrageiras estudadas, e;

$\mathrm{O}$ aumento do perfilhamento das plantas nas unidades experimentais em decorrência dos ciclos de produção (cortes) influenciou na produção de massa seca e extração de nutrientes das forrageiras.

\begin{abstract}
Due to limited information on the ability to extract nutrients from the soil by forage fertigated with effluent, the present study aimed to evaluate the extraction capacity of soil macronutrients and sodium by fodder Tifton 85 (Cynodon spp) and Marandu Grass (Brachiaria brizantha) fertigated with treated domestic sewage on three production cycles in greenhouse conditions. The experiments were performed in a completely randomized design, one for each species, both in split plot layout $4 x 3$ with 5 repetitions, four fertigation with treated domestic sewage at dosages of 20, 40, 60 and $80 \mathrm{~kg}$ ha-1 nitrogen in plots and subplots, three production cycles where cuts were made in the forage plant material, always 30 days after the completion of the application of treated domestic sewage. After each cut, the treatments were applied again and cut plant material were quantified foliar levels and sodium extracted from the soil by forage. The results showed that the application of nitrogen through the treated domestic sewage and production cycles (cuts) positively affected the dry matter production and extraction of macronutrients and sodium by plants and Tifton 85 on the Marandú Grass.
\end{abstract}

KEYWORDS: Water reuse. Wastewater. Cynodon spp. Brachiaria brizantha.

\title{
REFERÊNCIAS
}

APHA. AMERICAN PUBLIC HEALTH ASSOCIATION. Standard methods for the examination of water and wastewater. 19.ed. New York: APHA-WWA-WPCR, 1995. 1268p.

BELTRÃO, J.; SANTOS, R.; CORREIA, P. J. Combined effects of potassium and wastewater application on the yield and quality of Bermuda grass (Cynodon dactylon) in the Mediterranean regions. Wseas Transactions on Environment and Development. Napoli, v. 4, n. 9, p. 726-735, 2008.

BRAZ, A. J. B. P; SILVEIRA, P. M.; KLIEMANN, H. J.; ZIMMERMANN, F. J. P. Acumulação de nutrientes em folhas de milheto e dos capins braquiária e Mombaça. Pesquisa Agropecuária Tropical, Goiânia, v. 34, n. 2, p. 83-87, 2004. 
BENETT, C. G. S.; BUZETTI, S.; SILVA, K. S.; BERGAMASCHINE, A. F., FABRICIO, J. A.; Produtividade e composição bromatológica do capim-marandu a fontes e doses de nitrogênio. Revista Ciência e Agrotecnologia, Lavras, v. 32, n. 5, p. 1629-1636, 2008.

CABRAL, J. R.; FREITAS, P. S.L.; REZENDE, R.; MUNIZ, A. S.; BERTONHA, A. Impacto da água residuária de suinocultura no solo e na produção de capim-elefante. Revista Brasileira de Engenharia Agrícola e Ambiental, Campina Grande, v. 15, n. 8, p. 823-831, 2011.

COSTA, M.; BELTRAO, J.; DIONISIO, L. P. C.; GUERRERO, C. A. C.; BRITO, J. M. C.; MATOS, L.; REBELO, J.; GAMITO, P. Response of fairway grasses of golf courses to potable water irrigation as compared to wastewater application. Acta Horticulturae, Bruxelas, n. 573, p. 357-362. 2002.

COSTA, K. A. P.; OLIVEIRA, I. P.; SEVERIANO, E. C.; SAMPAIO, F. M. T.; CORRIJO, M. S.; RODRIGUES, C. R. Extração de nutrientes pela fitomassa de cultivares de Brachiaria brizantha sob doses de nitrogênio. Ciência Animal Brasileira, Goiânia, v. 11, n. 2, p. 307-314, 2010.

EMBRAPA- EMPRESA BRASILEIRA DE PESQUISA AGROPECUÁRIA. Manual de análises químicas de solos, plantas e fertilizantes. Brasília: Embrapa Comunicação para Transferência de Tecnologia, 2009. 627 .

ERTHAL, V. J. T.; FERREIRA, P. A.; PEREIRA, O. G.; MATOS, A. T. Características fisiológicas, nutricionais e rendimento de forrageiras fertigadas com água residuária de bovinocultura. Revista Brasileira de Engenharia Agrícola e Ambiental, Campina Grande, v. 14, n. 5, p. 458-466, 2010.

FONSECA, A. F.; MELFI, A. J.; MONTEIRO, F. A.; MONTES, C. R.; ALMEID, V. V.; HERPIN, U. Treated sewage effluent as a source of water and nitrogen for Tifton 85 bermudagrass. Agricultural Water

Management, Amsterdam, v. 87, n. 3, p. 328-336, 2007. http://dx.doi.org/10.1016/j.agwat.2006.08.004

MARSCHNER, H. Mineral nutrition of higher plants. 2. ed. London: Academic Press, 1995. 889 p.

MATOS, A. T.; PINTO, A. B.; PEREIRA, O. G.; BARROS, F. M. Extração de nutrientes por forrageiras cultivadas com água residuária do beneficiamento de frutos do cafeeiro. Revista Ceres, Viçosa, v. 52, n. 303, p. $675-688,2005$.

MATOS, A. T.; ABRAHÃO, S. S.; PEREIRA, O. G. Desempenho agronômico de capim tifton 85 (cynodon spp) cultivado em sistemas alagados construídos utilizados no tratamento de água residuária de laticínios. Revista Ambiente \& Água, Taubaté, v. 3, n. 1, p. 43-53, 2008.

MATOS, A. T.; FREITAS, W. S.; LO MONACO, P. A. V. Capacidade extratora de diferentes espécies vegetais cultivadas em sistemas alagados utilizadas no tratamento de águas residuárias da suinocultura. Revista ambiente \& água, Taubaté, v. 4, n. 2, p. 31-45, 2009.

MATOS, A. T.; FREITAS, W. S.; LO MONACO, P. A. V. Eficiência de sistemas alagados construídos na remoção de poluentes de águas residuárias da suinocultura. Revista ambiente \& água, Taubaté, v. 5, n. 2, p. 119-132, 2010.

MEURER, E.J. Potássio. In: FERNANDES, M.S. (Ed.). Nutrição Mineral de Plantas. Viçosa:SBCS. 2006, p 281-299.

MIRANDA, F. R.; CAVALCANTE, R. R. R.; RIBEIRO, E. M.; LIMA, R. N. Uso de efluentes da carcinicultura na irrigação de Panicum maximum cvs. Tanzânia e Mombaça. Revista Ciência Agronômica, Fortaleza, v. 41, n. 1, p. 46-52, 2010. 
PREMAZZI, L. M.; MONTEIRO, F. A.; CORRENTE, J. E. Tillering of Tifton 85 bermudagrass in response to nitrogen rates and time of application after cutting. Scientia Agricola, Campinas, v. 60, p. 565-571, 2003. http://dx.doi.org/10.1590/S0103-90162003000300023

PREMAZZI, L. M., MONTEIRO, F. A., OLIVEIRA, R. F. Crescimento de folhas do capim-bermuda tifton 85 submetido à adubação nitrogenada após o corte. Revista Brasileira de Zootecnia, v. 40, n. 3, p. 518-526, 2011. http://dx.doi.org/10.1590/S1516-35982011000300008

PREZOTTI, L. C; GOMES, J. A; DADALTO, G. G; OLIVEIRA, J. A. DE. Manual de recomendação de calagem e adubação para o Estado do Espírito Santo $5^{\text {a }}$ aproximação. Vitória: SEEA/INCAPER/CEDAGRO, 2007. 305p.

VESI, A. C.; PRIMAVESI, O.; CORRÊA, L. A.; CANTARELLA, H.; DA SILVA, A. G.; FREITAS, A. R.; VIVALDI, L. J. Adubação Nitrogenada em Capim-Coastcross: Efeitos na Extração de Nutrientes e Recuperação Aparente do Nitrogênio. Revista Brasileira de Zootecnia, Brasília, v. 33, n. 1, p. 68-78, 2004. http://dx.doi.org/10.1590/S1516-35982004000100010

PRIMAVESI, A. C.; PRIMAVESI, O.; CORRÊA, L. A.; SILVA, A. G.; CANTARELLA, H. Nutrientes na fitomassa de capim-marandu em função de fontes e doses de nitrogênio. Ciência e Agrotecnologia, Lavras, v. 30, n. 3, p. 562-568, 2006.

QUEIROZ, F. M.; MATOS, A. T.; PEREIRA, O. G.; OLIVEIRA, R. A.; LEMOS, A. F. Características químicas do solo e absorção de nutrientes por gramíneas em rampas de tratamento de águas residuárias da suinocultura. Engenharia na Agricultura, Viçosa, v. 12, n. 2, p. 77-90, 2004.

SANTOS, K. D.; HENRIQUE, I. N.; SOUSA, J. T. DE; LEITE, V. D. Utilização de esgoto tratado na fertirrigação agrícola. Revista de Biologia e Ciências da Terra. Campina Grande, Suplemento Especial, n. 1, p. 1-7, 2006.

VILLELA JUNIOR, L. V. E.; ARAÚJO, J. A. C.; FACTOR, T. L. Efeito da utilização do efluente de biodigestor no cultivo hidropônico do meloeiro. Revista Brasileira de Engenharia Agrícola e Ambiental, Campina Grande, v. 7, p. 72-79, 2003.

ZIMMER, A.; SILVA, M. P.; MAURO, R. Sustentabilidade e impactos ambientais da produção animal em pastagens. In: PEIXOTO, A. M.; MOURA, J. C.; PEDREIRA, C. G. S.; FARIA, V. P. (Ed.) Inovações Tecnológicas no Manejo de Pastagens. Piracicaba: FEALQ, cap. 2, 2002, p. 31-58. 